\title{
Piecing the evidences: Barriers to utilization of Antenatal Care Services by Currently Married Women in Rural Uttarakhand- A community-based study
} Ruchi Juyal ${ }^{1}$, Jayanti Semwal ${ }^{2}$, Sunil Dutt Kandpal ${ }^{3}$, Ashok Kumar Srivastava ${ }^{4}$, Deep Shikha ${ }^{5}$, Vidisha Vallabh ${ }^{6}$ ${ }^{1}$ Professor, Department of Community Medicine, Himalayan Institute of Medical Sciences, Swami Rama Himalayan University Dehradun, Uttarakhand; ${ }^{2}$ Professor and Head, Department of Community Medicine, Himalayan Institute of Medical Sciences, Swami Rama Himalayan University Dehradun Dehradun, Uttarakhand; ${ }^{3}$ Professor and Head, Department of Community Medicine, Dr Ram Manohar Lohia Institute of Medical Sciences, Lucknow, Uttar Pradesh; ${ }^{4}$ Professor, Department of Community Medicine, Himalayan Institute of Medical Sciences, Swami Rama Himalayan University Dehradun, Uttarakhand; ${ }^{5}$ Associate Professor, Department of Community Medicine, Himalayan Institute of Medical Sciences, Swami Rama Himalayan University Dehradun, Uttarakhand; ${ }^{6}$ Assistant Professor, Department of Community Medicine, Himalayan Institute of Medical Sciences, Swami Rama Himalayan University Dehradun, Uttarakhand

\begin{tabular}{|c|c|c|c|c|c|c|c|c|}
\hline Abstract & Introduction & Methodology & Results & Conclusion & References & Citation & \multicolumn{2}{|c|}{ Tables / Figures } \\
\hline \multicolumn{9}{|c|}{ ing Author } \\
\hline \multicolumn{8}{|c|}{$\begin{array}{l}\text { Dr Ruchi Juyal, Professor, Department of Community Medicine, Himalayan Institute of Medical Sciences, } \\
\text { SRHU, Dehradun, Uttarakhand } \\
\text { E Mail ID: aniruchi08@gmail.com }\end{array}$} & 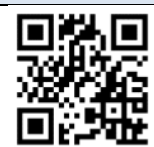 \\
\hline
\end{tabular}

\section{Citation}

Juyal R, Semwal J, Kandpal SD, Srivastava AK, Shikha D, Vallabh V. Piecing the evidences: Barriers to utilization of Antenatal Care Services by Currently Married Women in Rural Uttarakhand- A community-based study. Indian J Comm Health. 2020;32(1):114-119.

Source of Funding: Department of Health Research (DHR) Conflict of Interest: None declared

\section{Article Cycle}

Received: 19/12/2019; Revision: 14/01/2020; Accepted: 09/03/2020; Published: 31/03/2020 This work is licensed under a Creative Commons Attribution 4.0 International License.

\section{Abstract}

Background: High maternal mortality has always been an area of concern in developing countries. Availability and availment of adequate antenatal care play a significant role in reduction of maternal deaths. Aim \& Objective: To know the extent of antenatal care (ANC) services utilization by the currently married women of rural Uttarakhand during their last pregnancy, to find the barriers for utilization of ANC services and correlate the socio-demographic variables with the non-utilization of ANC services. Methods and Material: This correlational study was conducted in rural areas of 3 randomly selected districts in Uttarakhand. Multistage stratified and simple random samplings were used for area selection and PPS technique was used to recruit the participants. Overall, 637 currently married women (CMW) who delivered in last 5 years prior to survey, were interviewed by trained social workers. Chi-square test was used to ascertain association between variables and regression analysis was done to adjust for confounding associations. Results: Overall 496 (77.9\%) women availed one or more ANC services during their last pregnancy, but the complete package was availed by only 210 (33\%) of the CMW. Majority of the women who did not avail any ANC services were older, illiterate, labourer, spouse of labourer/ unemployed person and belonged to lower socio-economic status. Unawareness was the most commonly cited reason for not availing ANC services followed by financial issues and unfelt need. Conclusions: Women in Uttarakhand are pliant to ANC services, but there is a need to create demand for it by increasing awareness and improving the quality of ANC services.

\section{Keywords}

Antenatal Care; Married Women; Rural

\section{Introduction}

In 2015, approximately 303000 women died all over the world during and following pregnancy and childbirth. Almost all of these deaths occurred in low to middle income countries and most of these deaths could have been averted as the necessary medical interventions exist and are well known(1). Over the past few decades, though
India has made significant progress in maternal health, but this decline has decelerated and the country continues to contribute almost one-quarter of maternal deaths globally(2).

It is a well-known fact that most of the maternal deaths are avertible, as access to good antenatal care (ANC) in pregnancy, skilled care during delivery, and care and support in the postpartum period can avert many 
complications. As a child's health is very closely linked to its mother's, right from conception through to birth, an effective care during the antenatal period decreases the chance of a negative outcome of the pregnancy(3).

The World Health Organization (WHO) recommends at least four ANC visits during pregnancy to check for the wellbeing of the mother and foetus, providing counselling to mothers about the care they should take during pregnancy and also in preparation for childbirth(4). It ensures birth preparedness and complication readiness as well as provides other essential services which ensure the wellbeing of mother and baby(5).

However, utilization of these services is not universal, even in settings where they are widely available. Data show that the utilization of ANC services in India has increased substantially over time, $66 \%$ to $77 \%$ from National Family Health Survey-2 (NFHS-2) to NFHS-3*(6). According to NFHS-4, $34.9 \%$ of pregnant women received at least 4 ANC visits in the state of Uttarakhand(7).

As antenatal care is crucial for the health of both the mother and the new born, it is important to analyse the possible factors acting as a barrier to its utilization, if any. Therefore, this paper aims to identify factors associated with utilization of ANC services as well as possible barriers to it. This is a smaller part of the project supported by the department of Health Research, Government of India.

\section{Aims \& Objectives}

- To know the extent of antenatal care services utilization by the currently married women of rural Uttarakhand during their last pregnancy.

- To find the barriers for utilization of ANC services.

- To correlate the socio-demographic variables with the non-utilization of ANC services.

\section{Material \& Methods}

This study was carried out as a research project approved and funded by the Department of Health and Research (DHR), Government of India. It was a correlational study, conducted amongst currently married women of reproductive age group (15-49 years) of Uttarakhand state to know their general and reproductive health seeking behaviour and perceived barriers to it. The eligible women were recruited by using multistage stratified and simple random sampling with probability proportional to size (PPS). A sample size of 1600 was calculated by assuming the prevalence of health seeking behavior as $50 \%$, as studies from this area related to health seeking behaviour are scarce. Sample size was calculated by using formula $4 \mathrm{pq} / \mathrm{I2}$ (Where $\mathrm{p}=$ prevalence, $q=100-\mathrm{p}$ and $\mathrm{l}=5 \%$ of $p)$.

The study area comprised of three randomly selected blocks in three districts of the state. Uttarakhand is a hilly state which can be broadly divided into three geographic zones, the upper Himalayas, the mid Himalayas and the foothills. From each zone, one district was selected randomly (i.e. three districts in all). Then one block $\mathrm{CHC}$ area followed by one PHC area was selected randomly in each district. The study population (currently married women in reproductive age group) of the selected PHC area were line listed and then the sample size was reached by using PPS technique (in different age groups).

For data collection, a tool (schedule) was developed to gather information related to socio-demographic details, reproductive health, health seeking behaviour and barriers to it etc. Social workers were trained by investigators in interview and Focus Group Discussion techniques. Pretesting of the data collection tool was done. Trained social workers interviewed the respondents by using finalized pretested structured data collection tool after taking consent. Those not giving consent were excluded from the study. From time to time supervision was done by the investigators in the field and minimum $10 \%$ of the forms were checked randomly in all the three areas to check authenticity of data.

Data so collected was entered in SPSS 22.0 software programme by the data entry operator. Suitable statistical tests were applied to the data to find out the significance of association between variables. A significant $p$-value was set at 0.05 .

\section{Results}

This paper presents the findings on the antenatal care services seeking behaviour of currently married women (CMW) in the reproductive age along with its barriers, if any, in selected areas of the state of Uttarakhand. Overall, $534 \mathrm{CMW}$ in the reproductive age were interviewed from each of the three districts namely Pauri, Uttarkashi and Udham Singh Nagar, thus completing the sample size of 1602. Women were selected in different age group according to their proportions in districts. For this research publication we analysed data from $637 \mathrm{CMW}$, who conceived/delivered in the past 5 years preceding the survey. The finding related to their last pregnancy are being presented in this paper.

ANC services were availed by 496 (77.9\%) women in their last pregnancy. It was seen that only $33.0 \%$ of the responders (210 women) received full ANC care and 286 (44.9\%) received incomplete ANC care during their last pregnancy.

The mean age of women who did not use any ANC services during their last pregnancy was $30.86 \pm 7.837$ years, which was higher than those who took ANC services (26.14 \pm 4.246 years). It is clear from (Table-1) that younger women availed ANC services more as compared to older women during their last pregnancy and this difference was found to be highly significant statistically. Hindu women had maximum utilization of ANC services, while least use was seen in Muslim women. (Figure-1)

Significantly higher proportion of women who were illiterate, labourer by occupation, spouse of illiterate, living in nuclear families and belonging to lower most socio-economic status did not avail any ANC services. 
ANC services were not availed by 141 interviewed women. When they were asked about the reason for not availing these services, unawareness about availability and importance of ANC services was the most commonly cited reason by 46 women (33\%). About $30 \%$ of the women (41) reported having problems with arranging money (for transportation as well as other expenses) to go for the ANC services, while $22 \%$ (31) felt no need for ANC services (Figure-2). About $8 \%$ of the women (11) claimed that they could not go for ANC because of the lack of easy availability of transport facilities to the service providers. Few women also cited uncordial behaviour of the health personnel for not wanting to go the health centres.

Unawareness regarding significance of antenatal services was found to be increasing in older age group (Table-2). Younger women, who did not avail ANC services were either not willing for it (despite of being aware) or quoted financial constraints as the main limitation. Lack of awareness was the main reason for non-availment of ANC services in Hindu women, while Muslim and Sikh women held their financial status accountable for this. Women who were illiterate or had education upto 5 years, were either not aware of the need for ANC services or had financial constraints, while women with higher education felt no need for it. There was no significant difference in the reasons for non-availment of ANC services according to the occupational status of respondents, type of families or Socio-economic status.

On doing regression analysis, age, education of respondent and spouse, religion, caste and type of family were found to be significantly associated with the utilization of antenatal care(Table-3).

\section{Discussion}

ANC services ensure good care of the mother's health as well as the development of the unborn baby. They allow for the promotion of good health of mother and foetus duo as well as early detection and treatment of complications. Inadequate care during pregnancy interferes in the continuum of care, and affects both mother and the baby.

In our study population, the ANC services were availed by $78 \%$ of the women in their last pregnancy, which is similar to NFHS-4 findings for Uttarakhand state (7). However, this is lower than the NFHS -4 survey records in India, where the proportion of women (age 15-49) who received ANC, has risen from $77 \%$ in NFHS-3 to $84 \%$ in NFHS-4 (8). Likewise in a survey done in recently delivered women in urban slums of Delhi, it was seen that almost $80 \%$ women received some form of $A N C(9)$.

As far as number of ANC visits are concerned, only about $33 \%$ of the surveyed women reported having received 4 or more ANC visit which is in concordance with Uttarakhand data (31\%) from NFHS-4(7). Rejoice and Ravishankar reported in their analysis of NFHS-3 findings, that $9.4 \%$ of the women in Karnataka did not receive any kind of ANC during their pregnancy, while it was only $0.9 \%$ in Tamil Nadu(10). In a study from rural Lucknow, it was found that $85.5 \%$ of the beneficiaries surveyed received at least three antenatal care services from any health facility, which is much higher than our study (11).

In Nigeria, 2013 Nigeria Demographic and Health Survey (DHS) revealed that the overall ANC coverage stood at $61 \%$ but $54 \%$ of the women received full antenatal care (12). Similarly, in Nepal, DHS 2011 findings revealed that $85 \%$ of the surveyed women had at least one ANC visit and almost half of those had four or more visits (13). The reason for lower full ANC coverage in our study may be that in hilly areas it is difficult to go for frequent ANC visits, owing to the non-availability of health facility nearby, lack of health personnel posted at health facilities due to difficult terrain or difficulty in getting transport as well in arranging money for transport. It was found that distance of health facility and hence problem in getting transport facilities was a big factor in non-availment of ANC services in our study.

Although, the factors deterring the utilization of health services are associated with the characteristics or quality of the services, but often it is also linked to the characteristics of the users and circumstances and hence vary from place to place. These may relate to the sociodemographic, economic and environmental characteristics of the individuals.

ANC behaviour in our study was significantly determined by age of the respondent, literacy status, lower earning occupation of the woman as well as the spouse and lower socio-economic status. A statistically significant reduction was observed in the proportion of women obtaining ANC services with increasing parity and number of living children. We report that lack of knowledge, finance related problems (for transportation as well as other expenses) for the ANC services and no felt need for ANC services were the main reasons for non-availment of ANC services among CMW in our study.

Srivastava $A$ et al concluded that maternal health care service utilization in their study was significantly associated with small family size, lower birth order, nuclear family, higher socio-economic status, woman's education and husband's occupation (14).

A meta-analysis from the DHS conducted in Bangladesh, India, Pakistan, Kenya, Nigeria, and Tanzania revealed that within each country, the poorer, less educated and rural women had higher unmet need for maternal care services. Service-related factors (accessibility in terms of cost and distance) and sociocultural factors (e.g., did not perceive the need for the services and objections from husband and family) also posed as barriers to antenatal care and institutional delivery (15).

Similar to our study, social status and distance of the health facility were found to be barriers towards seeking antenatal care especially among poor women who could not afford transportation fee to health facilities in Nigeria. 
Also, increasing utilization of maternal health services was found among younger women, low parity women and women with high income husbands (16). In yet another study from Nigeria, authors concluded that three reasons central to non-utilization of ANC services were: "Problems with getting money to go to health facilities", "Farness of ANC service providers" and "Unavailability of transport to reach the ANC providers" quite similar to our study (17).

\section{Conclusion}

The coverage of ANC services in the studies area was found to be about 78\%, which is similar to NFHS-4 data for Uttarakhand, but full coverage is still low. Increasing age, illiteracy, and poverty were found to be strongly associated with non-availment of ANC services. Unawareness was the most commonly cited reason for not availing ANC services, followed by financial issues and unfelt need. Few women also cited uncordial behaviour of the health personnel for not wanting to go the health centres.

\section{Recommendation}

There is a need to create demand for availment of ANC services among women of Uttarakhand. This can be done by spreading awareness about the importance of ANC services for the welfare of the mother as well as for the development of the child. For this, we must focus on addressing financial barriers and improving the quality of ANC services. This will lead to improved client satisfaction, thus ensuring maximal contacts between women and ANC providers.

\section{Limitation of the study}

All the information on availment of antenatal services was based on recall method which might have led to recall bias. Also, we did only quantitative assessment of service utilization.

\section{Relevance of the study}

This study provides us the reasons which act as barrier to availment of ANC services by women in this difficult terrain hilly state. Appropriate and timely action should be taken to address these issues as well as to empower the women, so that maternal mortality can be reduced in the state.

\section{Authors Contribution}

All authors have contributed equally.

\section{Acknowledgement}

The authors are thankful to the department of Health Research (DHR), GOI for granting funds for carrying out this project. We are also grateful to the Swami Ram Himalayan University, Dehradun for permitting us to carry out this research project and providing with the necessary support. We acknowledge the cooperation of all the women who participated in this survey and hard work of our health workers, who surveyed relentlessly in difficult terrains and bad weather.

\section{References}

1. Alkema L, Chou D, Hogan D, Zhang S, Moller A-B, Gemmill A, et al. Global, regional, and national levels and trends in maternal mortality between 1990 and 2015,. Lancet (London, England). 2016;387(10017):462-74.

2. Maternal mortality ratio (modeled estimate, per 100,000 live births) | Data [Internet]. [cited 2019 Sep 3]. Available from: https://data.worldbank.org/indicator/sh.sta.mmrt

3. Gülmezoglu AM, Lawrie TA, Hezelgrave N, Oladapo OT, Souza JP, Gielen $\mathrm{M}$, et al. Interventions to Reduce Maternal and Newborn Morbidity and Mortality. In: Disease Control Priorities, Third Edition (Volume 2): Reproductive, Maternal, Newborn, and Child Health. The World Bank; 2016. p. 115-36.

4. Benova L, Tunçalp Ö, Moran AC, Campbell OMR. Not just a number: Examining coverage and content of antenatal care in low-income and middle-income countries. BMJ Glob Heal. 2018 Mar 1;3(2).

5. Lincetto O, Mothebesoane-Anoh S, Gomez P, Munjanja S. Antenatal Care. In: Lawn J KK, editor. Opportunities for Africa's Newborns: practical data, policy and programmatic support for newborn care in Africa. WHO; 2006. p. 51-62.

6. International Institute for Population Sciences. NFHS-3: Summary of Findings [Internet]. [cited 2019 Sep 4]. Available from: http://rchiips.org/nfhs/NFHS-3 Data/VOL-1/ Summary of Findings (6868K).pdf

7. Health NF. National Family Health Survey (NFHS-4) 2015-16, Uttarakhand. 2018.

8. International Institute for Population Sciences. National Family Health Survey (NFHS-4) 2015-16 India [Internet]. International Institute for Population Sciences (IIPS) and ICF. 2017. Available from: http://rchiips.org/NFHS/NFHS-4Reports/India.pdf

9. Ghosh-Jerath S, Devasenapathy N, Singh A, Shankar A, Zodpey S. Ante natal care (ANC) utilization, dietary practices and nutritional outcomes in pregnant and recently delivered women in urban slums of Delhi, India: an exploratory cross-sectional study. Reprod Health. 2015 Mar 20;12(1).

10. Ravishankar AK, Rejoice PR. Differentials in Maternal Health Care Service Utilization: Comparative Study Between Tamilnadu and Karnataka. World Appl Sci J. 2011;14(11):1661-9.

11. Roy M, Mohan U, Singh S, Singh V, Srivastava A. Determinants of utilization of antenatal care services in rural Lucknow, India. J Fam Med Prim Care. 2013;2(1):55.

12. Nigeria. NIGERIA DEMOGRAPHIC AND HEALTH SURVEY 2013 National Population Commission Federal Republic of Nigeria Abuja. 2014.

13. Joshi C, Torvaldsen S, Hodgson R, Hayen A. Factors associated with the use and quality of antenatal care in Nepal: A population-based study using the demographic and health survey data. BMC Pregnancy Childbirth. 2014 Mar 3;14(1).

14. Srivastava A, Mahmood S, Mishra P, Shrotriya V. Correlates of maternal health care utilization in Rohilkhand Region, India. Ann Med Health Sci Res. 2014;4(3):417.

15. Tey NP, Lai SL. Correlates of and barriers to the utilization of health services for delivery in South Asia and Sub-Saharan Africa. Sci World J. 2013;2013.

16. Yar I, Said I, Yar IS. KNOWLEDGE AND BARRIERS IN UTILIZATION OF MATERNAL HEALTH CARE SERVICES IN KANO STATE, NORTHERN NIGERIA [Internet]. Vol. 1, European Journal of Biology and Medical Science Research. 2013 [cited 2019 Sep 4]. Available from: www.ea-journals.org

17. Fagbamigbe AF, Idemudia ES. Barriers to antenatal care use in Nigeria: Evidences from non-users and implications for maternal health programming. BMC Pregnancy Childbirth. 2015 Apr $17 ; 15(1)$. 


\section{Tables}

\section{TABLE 1 ANC SERVICES SEEKING BEHAVIOUR BY SOCIO-DEMOGRAPHIC CHARACTERISTICS}

\begin{tabular}{|c|c|c|c|c|c|c|}
\hline \multirow[t]{2}{*}{ Variables } & \multicolumn{3}{|c|}{ ANC services during last pregnancy } & \multirow{2}{*}{$\begin{array}{c}\text { Chi-square value, df , } \\
\text { p value }\end{array}$} & \multirow[t]{2}{*}{ OR } & \multirow[t]{2}{*}{$\mathrm{Cl}$} \\
\hline & User (496) & Non-User (141) & Total (637) & & & \\
\hline \multicolumn{7}{|l|}{ Age } \\
\hline $15-29$ years & $389(85.3)$ & $67(14.7)$ & 456 & \multirow{2}{*}{$\begin{array}{l}\chi^{2}-51.569 \\
d f-1, p<0.0001\end{array}$} & \multirow[t]{2}{*}{4.0153} & \multirow[t]{2}{*}{$2.708-5.953$} \\
\hline $30-49$ years & $107(59.1)$ & 74 (40.9) & 181 & & & \\
\hline \multicolumn{7}{|l|}{ Religion } \\
\hline Hindu & $427(82.0)$ & $94(18.0)$ & 521 & \multirow{2}{*}{$\begin{array}{l}\chi^{2}-27.806 \\
d f-1, p<0.0001\end{array}$} & \multirow[t]{2}{*}{3.094} & \multirow[t]{2}{*}{$2.007-4.770$} \\
\hline Non-Hindu & $69(59.5)$ & $47(40.5)$ & 116 & & & \\
\hline \multicolumn{7}{|c|}{ Education of Respondent } \\
\hline Illiterate & $26(41.3)$ & $37(58.7)$ & 63 & \multirow{2}{*}{$\begin{array}{l}\chi^{2}-54.324 \\
d f-1, p<0.0001\end{array}$} & \multirow[t]{2}{*}{0.155} & \multirow[t]{2}{*}{$0.090-0.268$} \\
\hline Literate & $470(81.9)$ & $104(18.1)$ & 574 & & & \\
\hline \multicolumn{7}{|c|}{ Occupation of Respondent } \\
\hline Housemaker & $464(81.7)$ & $104(18.3)$ & 568 & \multirow{2}{*}{$\begin{array}{l}\chi^{2}-44.516 \\
d f-1, p<0.0001\end{array}$} & \multirow[t]{2}{*}{5.159} & \multirow[t]{2}{*}{$3.071-8.666$} \\
\hline Employed & $32(46.4)$ & $34(53.6)$ & 69 & & & \\
\hline \multicolumn{7}{|c|}{ Education of Spouse } \\
\hline Illiterate & $11(35.5)$ & $20(64.5)$ & 31 & \multirow{2}{*}{$\begin{array}{l}\chi^{2}-33.959 \\
d f-1, p<0.0001\end{array}$} & \multirow[t]{2}{*}{0.137} & \multirow[t]{2}{*}{$0.064-0.294$} \\
\hline Literate & $485(80.0)$ & $121(20.0)$ & 606 & & & \\
\hline \multicolumn{7}{|l|}{ Type of Family } \\
\hline Nuclear & $142(64.5)$ & $78(35.5)$ & 220 & \multirow{2}{*}{$\begin{array}{l}\chi^{2}-34.593 \\
d f-1, p<0.0001\end{array}$} & \multirow[t]{2}{*}{0.324} & \multirow[t]{2}{*}{$0.220-0.476$} \\
\hline Joint & $354(84.9)$ & $63(15.1)$ & 417 & & & \\
\hline \multicolumn{7}{|c|}{ Socio-economic status } \\
\hline Upper & $92(95.8)$ & $42(4.2)$ & 96 & \multirow{3}{*}{$\begin{array}{l}\chi^{2}-32.116 \\
d f-2, p<0.0001\end{array}$} & 1.156 & $0.918-1.187$ \\
\hline Middle & $95(86.4)$ & $15(13.6)$ & 110 & & 0.399 & $0.223-0.717$ \\
\hline Lower & $309(71.1)$ & $122(28.3)$ & 431 & & 1 & \\
\hline
\end{tabular}

\section{TABLE 2 NON-USERS OF ANC BY REASONS AND SOCIO-DEMOGRAPHIC CHARACTERISTICS}

\begin{tabular}{|c|c|c|c|c|c|c|c|}
\hline \multirow[t]{2}{*}{ Variables } & \multicolumn{6}{|c|}{ Reasons for non-use of ANC services } & \multirow{2}{*}{$\begin{array}{l}\text { Chi-Square } \\
\text { test }\end{array}$} \\
\hline & No felt need & $\begin{array}{l}\text { Distant health } \\
\text { facility }\end{array}$ & $\begin{array}{l}\text { Financial } \\
\text { constraints }\end{array}$ & $\begin{array}{l}\text { Lack of } \\
\text { awareness }\end{array}$ & $\begin{array}{l}\text { Family Non- } \\
\text { cooperation }\end{array}$ & Others & \\
\hline \multicolumn{8}{|l|}{ Age } \\
\hline $15-29$ years & $24(35.8)$ & $5(7.5)$ & $22(32.8)$ & $11(16.4)$ & $1(1.5)$ & $4(6.0)$ & \multirow{2}{*}{$\begin{array}{l}\chi^{2}-23.809, d f- \\
5, p-0.000\end{array}$} \\
\hline $30-49$ years & $7(9.5)$ & $6(8.1)$ & $19(25.7)$ & $35(47.3)$ & $4(5.4)$ & $3(4.1)$ & \\
\hline \multicolumn{8}{|l|}{ Religion } \\
\hline Hindu & $30(31.9)$ & $7(7.4)$ & $16(17.0)$ & $35(37.2)$ & $4(4.3)$ & $2(2.1)$ & \multirow{2}{*}{$\begin{array}{l}\chi^{2}-33.597, d f- \\
5, p-0.000\end{array}$} \\
\hline Non-Hindu & $1(2.1)$ & $4(8.5)$ & $25(53.2)$ & $11(23.4)$ & $1(2.1)$ & $5(10.6)$ & \\
\hline \multicolumn{8}{|c|}{ Education of Respondent } \\
\hline Illiterate & $2(5.4)$ & $3(8.1)$ & $14(37.8)$ & $15(40.5)$ & $1(2.7)$ & $2(5.4)$ & \multirow{2}{*}{$\begin{array}{l}\chi 2-8.686, d f- \\
5, p-0.122\end{array}$} \\
\hline Literate & $29(27.9)$ & $8(7.7)$ & $27(26.0)$ & $31(29.8)$ & $4(3.8)$ & $5(4.8)$ & \\
\hline \multicolumn{8}{|c|}{ Occupation of Respondent } \\
\hline Housemaker & $30(28.8)$ & $9(8.7)$ & $23(22.1)$ & $31(29.8)$ & $4(3.8)$ & $7(6.7)$ & \multirow{2}{*}{$\begin{array}{l}\chi^{2}-19.015, \\
5, p-0.002\end{array}$} \\
\hline Labourer & $1(2.7)$ & $2(5.4)$ & $18(48.6)$ & $15(40.5)$ & $1(2.7)$ & $0(0.0)$ & \\
\hline \multicolumn{8}{|c|}{ Education of Spouse } \\
\hline Illiterate & $1(5.0)$ & $0(0.0)$ & $6(30.0)$ & $10(50.0)$ & $1(5.0)$ & $2(10.0)$ & \multirow{2}{*}{$\begin{array}{l}\chi^{2}-8.369, \text { df- } \\
5, p-0.137\end{array}$} \\
\hline Literate & $30(24.8)$ & $11(9.1)$ & $35(28.9)$ & $36(29.8)$ & $4(3.3)$ & $5(4.1)$ & \\
\hline \multicolumn{8}{|c|}{ Type of Family } \\
\hline Nuclear & $15(19.2)$ & $6(7.7)$ & $23(29.5)$ & $26(33.3)$ & $3(3.8)$ & $5(6.4)$ & \multirow{2}{*}{$\begin{array}{l}\chi 2-1.422, d f- \\
5, p-0.922\end{array}$} \\
\hline Joint & $16(25.4)$ & 5 (7.9) & $18(28.6)$ & $20(31.7)$ & $2(3.2)$ & $2(3.2)$ & \\
\hline \multicolumn{8}{|c|}{ Socio-economic status } \\
\hline Upper & $2(50.0)$ & $1(25.0)$ & $0(0.0)$ & $1(25.0)$ & $0(0.0)$ & $0(0.0)$ & \multirow{3}{*}{$\begin{array}{l}\chi^{2}-16.846, d f- \\
10, p-0.078\end{array}$} \\
\hline Middle & $7(46.7)$ & $0(0.0)$ & $1(6.7)$ & $5(33.3)$ & $0(0.0)$ & $2(13.3)$ & \\
\hline Lower & $22(18.0)$ & $10(8.2)$ & 40 (32.8) & $40(32.8)$ & $5(4.1)$ & $5(4.1)$ & \\
\hline
\end{tabular}




\begin{tabular}{|c|c|c|c|c|}
\hline VARIABLE & B & P-value & OR & Cl \\
\hline \multicolumn{5}{|l|}{ Age group } \\
\hline $15-29$ years & -0.989 & 0.000 & 0.372 & $0.229-0.604$ \\
\hline $30-49$ years & 1 & & & \\
\hline \multicolumn{5}{|l|}{ Religion } \\
\hline Hindu & -0.416 & 0.112 & 0.660 & $0.395-1.102$ \\
\hline Non-Hindu & 1 & & & \\
\hline \multicolumn{5}{|c|}{ Education of respondent } \\
\hline Illiterate & 0.650 & .060 & 1.916 & $0.973-3.774$ \\
\hline Literate & 1 & & & \\
\hline \multicolumn{5}{|c|}{ Occupation of respondent } \\
\hline Housemaker & -0.703 & 0.024 & 0.495 & $0.269-0.911$ \\
\hline Employed & 1 & & & \\
\hline \multicolumn{5}{|c|}{ Education of spouse } \\
\hline Illiterate & 0.643 & 0.172 & 1.902 & $0.755-4.792$ \\
\hline Literate & 1 & & & \\
\hline \multicolumn{5}{|l|}{ Type of family } \\
\hline Nuclear & -0.651 & 0.005 & 0.522 & $0.330-0.824$ \\
\hline Joint & 1 & & & \\
\hline \multicolumn{5}{|l|}{ SES } \\
\hline Upper & -1.647 & 0.003 & 0.193 & $0.064-0.580$ \\
\hline Middle & -0.299 & 0.364 & 0.741 & $0.389-1.414$ \\
\hline Lower & 1 & 0.011 & & \\
\hline Constant & 1.067 & 0.001 & 4.989 & \\
\hline
\end{tabular}

\section{Figures}

\section{FIGURE 1 RESPONDENTS BY ANC VISITS DURING LAST PREGNANCY}

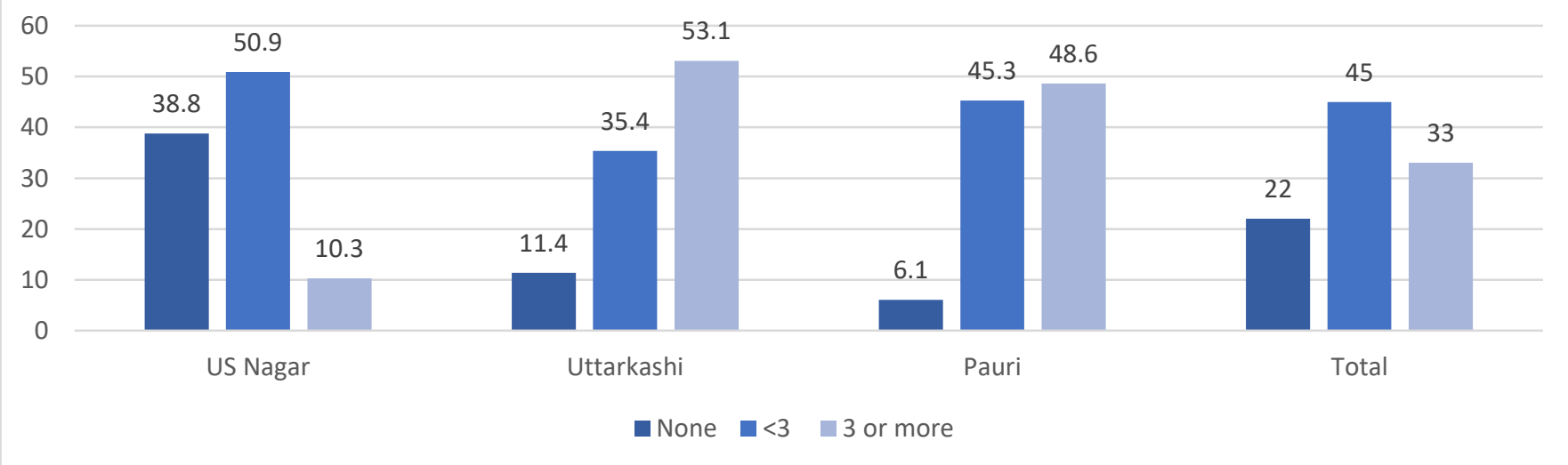

FIGURE 2 NON-USERS BY REASONS FOR NOT AVAILING ANTENATAL CARE

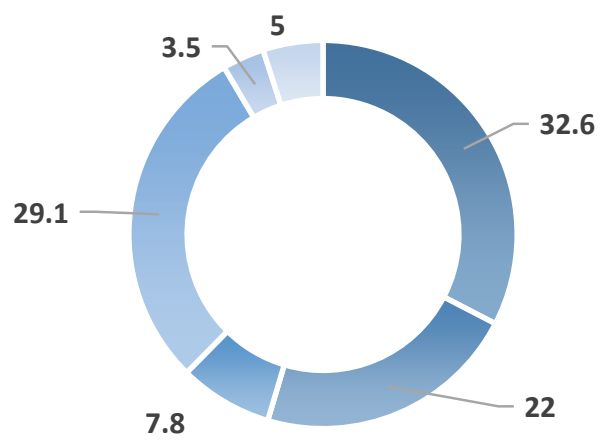

\footnotetext{
- Unawareness

- No need felt

- Lack of facilities nearby

- Financial problem

Non-cooperation of family

Multiple reasons
} 